\title{
The Symptoms of Autism Spectrum Disorders in Adolescence and Adulthood
}

\author{
Marsha Mailick Seltzer, ${ }^{1,5}$ Marty Wyngaarden Krauss, ${ }^{2}$ Paul T. Shattuck, ${ }^{1}$ \\ Gael Orsmond, ${ }^{3}$ April Swe, ${ }^{1}$ and Catherine Lord ${ }^{4}$
}

\begin{abstract}
This article describes the symptoms of autism spectrum disorders (ASD) manifested by 405 individuals between the ages of 10 and 53 years, all of whom had an ASD diagnosis. Data were collected using the Autism Diagnostic Interview-Revised (ADI-R) to assess the pattern of autism symptoms in adolescence and adulthood. Findings include that although virtually all sample members met the criteria for Autistic Disorder earlier in their childhood, just over half (54.8\%) would have met autism criteria if current scores were used to complete the diagnostic algorithm; that adolescents were more likely to improve in the Reciprocal Social Interaction domain than the adults, whereas the adults were more likely to improve in the Restricted, Repetitive Behaviors and Interests domain, and there were no differences in severity of symptoms between cohorts in the Communication domain; and that individual symptoms showed unique trajectories, with greatest symptom abatement between lifetime and current ADI-R ratings for speaking in at least three-word phrases and the least symptom improvement for having friendships. Findings were interpreted in the context of life course development, reformulations of diagnostic criteria, and changing service contexts for individuals with autism spectrum disorders.
\end{abstract}

KEY WORDS: Autism; ADI-R; symptoms; life course development.

\section{INTRODUCTION}

Descriptions of the manifestation of autism in childhood highlight the pervasive limitations of individuals with this disorder in the "basic building blocks for interpersonal relationships" (Travis \& Sigman, 1998 , p. 65). Although autism is an enduring condition that generally persists throughout the life course, little is known about the manifestations of the core deficits of autism in adolescence and adulthood. This knowledge

\footnotetext{
${ }^{1}$ Waisman Center, University of Wisconsin-Madison, Madison, Wisconsin.

${ }^{2}$ Heller School, Brandeis University, Waltham, Massachusetts.

${ }^{3}$ Sargent College, Boston University, Boston, Massachusetts.

${ }^{4}$ University of Michigan, Michigan, Ann Arbor, Michigan.

${ }^{5}$ Correspondence should be addressed to Marsha Mailick Seltzer, Waisman Center, University of Wisconsin-Madison, 1500 Highland Area, Madison, Wisconsin 53705-2280; e-mail: mseltzer@ waisman.wise.edu
}

is critical for life course research on individuals with autism and for an understanding of the effect of autism on the family and society (Schroeder \& LeBlanc, 1996). The purpose of this article is to describe the symptoms of autism spectrum disorders (ASDs) in adolescence and adulthood among a large sample of individuals $(n=405)$ between the ages of 10 and 53 years, all of whom had an ASD diagnosis.

Clinical accounts of the life course of individuals with ASDs (e.g., Kanner, 1971; Sperry, 2001; Tantam, 2000; Wolf \& Goldberg, 1986) describe great heterogeneity in development, with some individuals losing skills over time, others reaching a plateau in adolescence, and still others manifesting a pattern of continued development in adulthood. Adolescence is a time of increasing challenge for individuals with an ASD diagnosis and for their families, as this is when preparations must be made for the transition to adulthood. Fong, Wilgosh, and Sobsey (1993) identified six areas 
of parental concern during adolescence: behavioral concerns (obsessions, aggression, tantrums), social and communicative concerns (inappropriate or inadequate social skills), family-related concerns (restriction in family life, need for constant supervision), education and related concerns (choosing integrated versus specialized services, accessing behavior management services), concerns about relationships with professionals (ineffective communication, criticism or blame from professionals), and concerns about independence and future services (residential, vocational, and leisure services). Underlying all of these parental concerns are the symptoms of autism, which vary in severity from individual to individual and over time.

Why might the symptoms of autism appear to be different at different stages of life? There are multiple explanations. First, processes of maturation and development interact with the manifestation of the core symptoms of autism and affect the acquisition of skills (Burack, Charman, Yirmiya, \& Zelazo, 2001). Furthermore, because autism involves both the absence of behaviors associated with normal development (e.g., making eye contact, pointing to express interest) and the presence of qualitatively abnormal behaviors (e.g., compulsions, rituals; Lord, Rutter, \& LeCouteur, 1994), it is possible that different developmental trajectories characterize these two types of symptoms of the disorder.

Second, cross-sectional comparisons of individuals with autism at different life stages may reflect differences in diagnostic practices at different points in time. Since autism was first identified as a behavioral syndrome, the diagnostic criteria have changed considerably (Fombonne, 2001; Wing, 1993). In general, earlier diagnostic criteria were more narrow than are contemporary criteria, such that individuals diagnosed at earlier points in time had to have had more severe manifestations of the disorder to qualify as having autism than those diagnosed more recently (Magnusson \& Saemundsen, 2001; Volkmar, Cicchetti, Bregman, \& Cohen, 1992). Thus, cross-sectional differences between individuals at different life stages may reflect changing diagnostic norms, with adult cohorts continuing to have more severe symptoms than cohorts of adolescents or children, even if there are underlying processes of maturation and development. Furthermore, a number of follow-up studies of individuals with autism indicate that those who have less severe limitations, especially in language, tend to have better outcomes (for a review, see Howlin \& Goode, 1998). Because contemporary definitions have been more inclusive of individuals with less-severe language impairments than were definitions in use several decades ago, more recently diagnosed cohorts may be less impaired and may show greater gains during adolescence and adulthood than cohorts diagnosed previously.

Third, environmental influences may affect the manifestation of symptoms at any point in the life course. An ecological theory of autism argues that autism is not simply a characteristic of the individual but reflects a "disordered relationship between the person and the environment" (Loveland, 2001, p. 23). Furthermore, interventions, treatments, services, the family environment, and medications may all alter the course of development in individuals with ASDs (Lord \& McGee, 2001). Given recent increases in autism-specific services and educational interventions, such environmental influences may have benefitted younger cohorts more than their older counterparts (Lord \& McGee, 2001).

In this article, we provide cross-sectional comparisons of the symptoms currently manifested by adolescents and adults with ASD diagnoses and also draw on retrospective assessments of their most severe manifestation of symptoms. According to the DSM-IV-TR (American Psychiatric Association, 2000), for an individual to be given the diagnosis of autistic disorder, he or she has to demonstrate qualitative impairments in social interaction, communication, and restricted repetitive and stereotyped patterns of behaviors, interests, and activities; and delayed or abnormal functioning before age 3 years in social interaction, language, or symbolic or imaginative play. The Autism Diagnostic Interview-Revised (ADI-R; Lord et al., 1994) operationalizes the DSM-IV definition of autism by establishing thresholds defining qualitative impairments in social interaction, communication, and behavior. For most items, the ADI-R yields two ratings of the degree of impairment in multiple symptoms of autism: the degree of impairment at the present time and a "lifetime" rating of the most severe degree of impairment earlier or ever in the individual's life, often pegged at age $4-5$ years.

\section{Studies of Symptom Change}

A number of studies have used the ADI-R to compare ratings of current behavior with retrospective accounts of severity of symptoms during early childhood and thus to make inferences about changes in the manifestation of symptoms across the life course. For 
example, Piven, Harper, Palmer, and Arndt (1996) administered the ADI-R to parents of 38 high-IQ adolescents and adults with autism (age 13-28 years). On all three domains (communication, social, behavior), the ratings of current behavior were significantly less abnormal than the retrospectively assessed lifetime scores. Similarly, Boelte and Poustka (2000) administered the ADI-R to 93 individuals aged 15-37 years, with a mean age of 22.3 years. Current symptoms were milder than the lifetime ratings. The authors concluded that the symptoms improve over time, even though ASDs tend to be lifelong disabilities. The same approach was used by Gilchrist, Green, Cox, Burton, Rutter, and LeCouteur (2001), who reported $10 \%$ or more reduction in abnormality in current symptoms, as measured by the ADI-R, as compared with symptoms of early development, measured restrospectively.

In addition to studies comparing current symptoms with the most severe manifestation ever in an individual's lifetime, other studies, based primarily on clinical samples, have examined prospectively how the symptoms of autism change over the life course. Gillberg and Steffenberg (1987) reported an upsurge during adolescence in behavior problems and psychiatric symptoms, as well as the onset of seizures associated with puberty. However, the available data indicate that whereas adolescence is a high-risk period of life for individuals with autism, there is considerable improvement in adulthood. Rumsey, Rapoport, and Sceery (1985), in their review of the follow-up study literature, concluded that "the natural course of autism is gradual symptomatic improvement with persistent, residual, social impairments" (p. 465). For example, Venter, Lord, and Schopler (1992) reported that the sample members they followed up in adolescence or adulthood $(n=58)$ continued to have significant limitations in adaptive behavior but that their IQ scores had increased by almost 10 points since they were diagnosed in early childhood. Similar patterns were reported in two international studies. A Japanese study (Kobayashi \& Murata, 1988) concluded that many symptoms of autism improved over the life course, although adults with autism continue to struggle in multiple areas of functioning. A British study (Beadle-Brown, Murphy, Wing, Gould, Shah, \& Holmes, 2000) reported a pattern of significant improvements over an 11-year period in selfcare skills, communication skills, and educational achievements.

Piven et al. (1996) concluded that autism is a "lifelong disorder whose features change with development" (p. 527). Of their sample of 38 adolescents or adults with autism who had been diagnosed in early childhood, all but five continued to meet DSM-IV criteria for autism in adulthood, and even these five had persistent autistic characteristics. Most sample members improved from childhood to adolescence and adulthood, with $82 \%$ having improved in communication, $82 \%$ having improved in social interaction, and 55\% having reduced ritualistic and repetitive behaviors. Thus, improvement is a dominant, although not universal, pattern of change shown by persons with autism, existing alongside persistent impairments in multiple areas of functioning.

\section{Hypotheses}

To examine the manifestations of autism in adolescence and adulthood, we first examine the stability of the diagnosis of ASDs, as indicated by the extent to which the members of the sample continued to manifest the ADI-R profile consistent with the diagnosis they had received earlier in childhood. We hypothesize that significantly fewer individuals will meet diagnostic cutoffs for their current ratings than for their lifetime ratings. We further hypothesize that the proportion of individuals who no longer meet diagnostic criteria based on current scores will be higher among adolescents than adults. This, we suggest, is the result of the broadening of the diagnostic criteria of autism, which currently include less severely impaired individuals who are more likely to improve in their functioning over time.

Second, we examine the extent to which the symptoms of autism differ in severity between the lifetime ADI-R score and the current score and whether this difference varies by age cohort (adolescence, adulthood). Again, we hypothesize that current scores will reflect less severe symptomatology than lifetime scores, with the adolescent cohort showing greater improvement than the adult cohort.

Third, we investigate which symptoms of autism change the most over time and which are the most stable.

\section{METHODS}

\section{Sample}

The sample for the present analysis consists of 405 individuals with an ASD who are age 10 years and older. Half $(49.6 \%, \mathrm{n}=201)$ of the sample members 
live in Wisconsin, and the other half $(50.4 \%, \mathrm{n}=204)$ live in Massachusetts. All participants met two criteria in order to qualify for the study: first, they had to have received a diagnosis on the autism spectrum (Autistic Disorder, Asperger's Disorder, or Pervasive Developmental Disorder-Not Otherwise Specified [PDD-NOS]) from a medical, psychological, or educational professional, as reported by their parents, and second, their ADI-R lifetime algorithm profile had to be consistent with their reported ASD diagnoses. Individuals with Rett's Disorder, Childhood Disintegrative Disorder, tuberous sclerosis, and fragile $\mathrm{X}$ syndrome were excluded because each of these disorders has a distinct medical or developmental course.

The families of these 405 individuals with ASD diagnoses were recruited for the study through agencies, schools, diagnostic clinics, and the media. Informational packets were distributed to families who were invited to participate in the research. Identical recruitment procedures were used in Wisconsin and Massachusetts.

The sample of individuals with ASD averaged 21.74 years of age $(\mathrm{SD}=9.47)$ and was divided into two age cohorts: adolescents (age 10-21 years, $\mathrm{n}=251$, mean age $=15.71$ years, $\mathrm{SD}=2.94)$ and adults (age 22 years and older, $\mathrm{n}=154$, mean age $=31.57$ years, $\mathrm{SD}=8.10)$. The majority $(\mathrm{n}=296$, $73.1 \%$ ) of the sample members were male, reflective of the gender distribution in the population (American Psychiatric Association, 2000). Nearly two-thirds of the sample $(64.9 \%, \mathrm{n}=263)$ lived at home with their parents, and $142(35.1 \%)$ lived in a variety of residential settings away from their parents' home. More than half $(59.8 \%)$ of the sample had been given a diagnosis of mental retardation at some point in their life, according to parental report. Nearly all sample members were White, with only $7.4 \%$ persons of color.

The mothers, who were the primary respondents for this analysis, averaged 52.04 years of age $(\mathrm{SD}=10.55)$. Most $(78.4 \%)$ were currently married, and many $(66.7 \%)$ were employed outside of the home. The annual household income averaged $\$ 50,822$. Fully $72.8 \%$ were high school graduates, of whom more than half $(61.7 \%)$ had a bachelor's or an advanced degree. More than three-fourths $(72.8 \%)$ rated their health as good or excellent.

\section{Assessment Procedures}

The study design calls for four rounds of data to be collected from each family, with home visits scheduled every 18 months. At the first home visit (Time 1), the mother was interviewed. Included in the interview were the 37 items from a standard short form of the ADI-R (C. Lord, personal communication, February 1999), consisting of the items that comprise the ADI-R diagnostic algorithm. The ADI-R is a standardized investigator-based interview conducted with a primary caregiver that is based on the DSM-IV (American Psychiatric Association, 1994) and International Classification of Diseases (ICD-10; World Health Organization, 1990) criteria for autism. Behavioral descriptions given by the caregiver are coded by the interviewers as 0 (no abnormality), 1 (possible abnormality), 2 (definite autistic-type abnormality), and 3 (severe autistic-type abnormality). For these analyses, scores of 3 were recoded to 2, as recommended by Lord et al. (1994).

Summary scores were computed in three domains: Communication; Reciprocal Social Interaction; and Restricted, Repetitive Behaviors and Interests. For each domain, the individual received two scores: a score reflecting "current" levels of impairment in each domain, and a "lifetime" score reflecting whether there was impairment either at age 4 to 5 years or at any time in the individual's life ("ever"), depending on the item. (Note that the items measured at age 4-5 years reflect the absence of prosocial behaviors, whereas the "ever" items reflect the presence of abnormal behaviors.) A diagnosis of Autistic Disorder is indicated when "lifetime" scores meet prespecified cut-off points in each of the three domains, with verification that developmental delay was evident before the age of 36 months. To enhance recall of age 4 to 5 years' behavior, mothers were asked to prepare a brief written description, before the Time 1 interview, of their son or daughter's reciprocal social interaction, communication, and behavioral impairments at age 4 to 5 years.

The interviewers who administered the ADI-R participated in an approved ADI-R training program. All interviews were tape recorded. Inter-rater reliability between the interviewers and two supervising psychologists experienced in the diagnosis of autism and in the use of the ADI-R averaged 88\%. Past research has demonstrated the test-retest reliability, diagnostic validity, convergent validity, and specificity and sensitivity of the ADI-R (Hill et al., 2001; Lord et al., 1997).

Of the 405 individuals in the sample, 384 (94.8\%) met the criteria for Autistic Disorder. Case-by-case review of the other $5.2 \%(\mathrm{n}=21)$ of the sample determined that their ADI-R profile was consistent with their ASD diagnosis (i.e., for Asperger's Disorder, the 
individual had to have met the ADI-R cutoffs for Reciprocal Social Interaction and Restricted, Repetitive Behaviors and Interests, and for PDD-NOS, the individual had to have met the ADI-R cutoff for Reciprocal Social Interaction and at least one cutoff for impairments in Communication or Restricted, Repetitive Behaviors and Interests).

\section{Methods of Data Analysis}

For the first analysis, we used paired $t$-tests for each of the three domains to examine whether in adolescence or adulthood the sample members continued to manifest the ADI-R profile consistent with the diagnosis they received in childhood. The ADI-R cutoff scores were originally developed for the lifetime ratings only. However, we also applied them to the current ratings to contrast the two sets of ratings. An important caveat is needed regarding comparisons of ADI-R current and lifetime scores. For items that ask about the "worst ever" manifestation of symptoms (14 of the 37 items), an individual's current score will necessarily be equal to or lower than their worst-ever score, a constraint imposed by the structure of the measure. In addition, we contrast the adolescent and adult cohorts to determine whether the two age groups differed in the likelihood that their current ADI-R scores met diagnostic cut offs for each of the three domains.

For the second analysis, which examined the severity of the symptoms of autism, we conducted twoway repeated-measures multivariate analyses of variance (MANOVAs), univariate repeated-measures analyses of variance (ANOVAs), and univariate cross-sectional ANOVAs. For the repeated-measures MANOVAs and the ANOVAs, the factors were time point (lifetime ADI-R score versus current ADI-R score) and age cohort (adolescent versus adult). We used repeated-measures MANOVAs when the same symptom was rated for both the lifetime and the current degree of severity and when there were multiple dependent variables measuring the same construct, to reduce the risk of Type I error. These constructs included nonverbal communication (four items), verbal symptoms (four items), reciprocal social interaction (13 items), and restricted repetitive behaviors and interests (seven items). For each of these constructs, we also report summary scores (i.e., the sum of the items included in the MANOVA).

We used repeated-measures ANOVAs for the analysis of three items that were rated for both the lifetime and current degree of severity but that could not be grouped with other items (overall level of language, verbal rituals) or because the item was rated for only a subsample based on current age (friendships).

There were five items from the ADI-R that were rated at one point in time only (either for the lifetime or the current rating but not both). Three of these were Communication domain items measured at age 4 to 5 years (lifetime) only (spontaneous imitation, imaginative play, and imitative social play). These items were analyzed using one-way MANOVA, comparing the adolescent and adult cohorts with respect to the lifetime score. An additional item in the Communication domain (reciprocal conversation) was rated for the current score only. This item was analyzed using a one-way ANOVA to compare the adolescent and adult cohorts. Finally, a single item in the Reciprocal Social Interaction domain (imaginative play with peers) was rated for the lifetime score only and was analyzed using a one-way ANOVA to compare the adolescent and adult cohorts.

The third analysis examined on an item-by-item basis the percentage of individuals who had impairments in a given symptom for the lifetime ADI-R rating (i.e., received a score of 1 or 2) but who were rated as asymptomatic (i.e., received a score 0 ) at present. We further defined a symptom as showing substantial abatement between the lifetime and current scores if more than $20 \%$ of the sample who were ever symptomatic were currently asymptomatic. We used $\chi^{2}$ tests to compare the adolescent and adult samples in the probability of symptom abatement.

Throughout this article, the $p<.05$ level of significance was used. Although many analyses were conducted, the use of MANOVA with multiple related dependent variables reduces the risk of Type I error, as univariate effects are interpreted only when the multivariate $F$ is significant.

\section{FINDINGS}

\section{Stability of ASD Diagnostic Profiles}

We first examined the extent to which the members of the sample met the lifetime diagnostic cut offs of the ADI-R and compared this with current ratings. As shown in panel A of Table I, 391 members of the sample $(96.5 \%)$ met the cut offs in all three behavioral ADI-R domains for their lifetime score. Virtually all sample members met the diagnostic cutoffs for the Communication domain (99.5\%), the Reciprocal Social Interaction domain $(100 \%)$, and the 
Table I. Percentage of Sample Scoring Above Cutoffs on ADI-R Domains Based on Lifetime and Current Ratings $(n=405)$

\begin{tabular}{|c|c|c|c|c|c|c|}
\hline \multirow[b]{2}{*}{ Domain } & \multicolumn{3}{|c|}{ A. Lifetime Rating ( $\%$ above cut-off) } & \multicolumn{3}{|c|}{ B. Current Rating ( $\%$ above cut-off) } \\
\hline & $\begin{array}{l}\text { Total sample } \\
(\mathrm{n}=405)\end{array}$ & $\begin{array}{l}\text { Age } 10-21 \text { years } \\
(\mathrm{n}=251)\end{array}$ & $\begin{array}{l}\text { Age } 22-53 \text { years } \\
\quad(\mathrm{n}=154)\end{array}$ & $\begin{array}{l}\text { Total sample } \\
\quad(\mathrm{n}=405)\end{array}$ & $\begin{array}{l}\text { Age } 10-21 \text { years } \\
\quad(\mathrm{n}=251)\end{array}$ & $\begin{array}{l}\text { Age } 22-53 \text { years } \\
\quad(\mathrm{n}=154)\end{array}$ \\
\hline Communication & $99.5 \%(403)$ & $99.2 \%(249)$ & $100 \%$ & $67.9 \%(275)$ & $64.9 \%(163)$ & $72.7 \%(112)$ \\
\hline Reciprocal Social Interaction & $100 \%$ & $100 \%$ & $100 \%$ & $85.4 \%(346)$ & $81.7 \%(205)$ & $91.6 \%(141)$ \\
\hline $\begin{array}{l}\text { Restricted, Repetitive Behaviors } \\
\text { and Interests }\end{array}$ & $97.0 \%(393)$ & $98.4 \%(247)$ & $94.8 \%(146)$ & $87.7 \%(355)$ & $90.0 \%(226)$ & $83.8 \%(129)$ \\
\hline Age (before 3 years of age) & $97.8 \%(396)$ & $96.4 \%(242)$ & $100 \%(154)$ & $\mathrm{n} / \mathrm{a}$ & $\mathrm{n} / \mathrm{a}$ & $\mathrm{n} / \mathrm{a}$ \\
\hline All three behavioral domains & $96.5 \%(391)$ & $97.6 \%(245)$ & $94.8 \%(146)$ & $54.8 \%(222)$ & $54.2 \%(136)$ & $55.8 \%(86)$ \\
\hline $\begin{array}{l}\text { In two of three behavioral } \\
\text { domains }\end{array}$ & $3.5 \%(14)$ & $2.4 \%(6)$ & $5.2 \%(8)$ & $33.3 \%(135)$ & $30.7 \%(77)$ & $37.7 \%(58)$ \\
\hline $\begin{array}{l}\text { In one of three behavioral } \\
\text { domains }\end{array}$ & 0 & 0 & 0 & $9.9 \%(40)$ & $12.7 \%(32)$ & $5.2 \%(8)$ \\
\hline $\begin{array}{l}\text { In zero of three behavioral } \\
\text { domains }\end{array}$ & 0 & 0 & 0 & $2.0 \%(8)$ & $2.4 \%(6)$ & $1.3 \%(2)$ \\
\hline $\begin{array}{l}\text { All four domains } \\
\text { (behavioral and age) }\end{array}$ & $94.8 \%(384)$ & $94.8 \%(238)$ & $94.8 \%(146)$ & $\mathrm{n} / \mathrm{a}$ & $\mathrm{n} / \mathrm{a}$ & $\mathrm{n} / \mathrm{a}$ \\
\hline
\end{tabular}

Note: $\mathrm{n} / \mathrm{a}$, not applicable.

Restricted, Repetitive Behaviors and Interests domain $(97.0 \%)$.

In contrast, as shown in panel B of Table I, at present just over half of the sample members met all three behavioral cut offs for Autistic Disorder (54.8\%). Of the others, one-third (33.3\%) currently met the cut offs in two behavioral domains. The remaining 48 sample members no longer met the cut off for any diagnosis on the autism spectrum. Of these, 40 met the cut off in one behavioral domain only, and eight did not meet the cut off for any ADI-R behavioral domain at present.

Although the pattern of improvement was notable, the majority of the sample members continued to manifest symptoms of autism that met the diagnostic threshold. Considering each domain individually, two-thirds $(67.9 \%)$ of the sample currently scored above the cutoff for the Communication domain, and more than $85 \%$ remained above the cutoffs for the Reciprocal Social Interaction and the Restricted, Repetitive Behaviors and Interests domains.

We used paired $t$-tests to examine whether the sample members differed in their current versus lifetime likelihood of meeting the diagnostic cut off for autism. For all three domains, significantly fewer sample members met the diagnostic cut offs at present than in the past (Communication: $t=13.66, \mathrm{df}=404, p<.001$; Reciprocal Social Interaction: $t=8.30, \mathrm{df}=404$, $p<.001$; and Restricted, Repetitive Behaviors and Interests: $t=6.47, \mathrm{df}=404, p<.001$ ).
For the ratings of current symptoms (panel B of Table I), we compared the adolescent and adult cohorts to determine the extent to which the two age cohorts differed in the proportion of sample members who currently met the behavioral cutoffs for Autistic Disorder. For the Communication and the Restricted, Repetitive Behaviors and Interests domains, the adolescent and adult cohorts did not differ. For the Reciprocal Social Interaction domain, significantly fewer members of the adolescent cohort currently met the cut off than members of the adult cohort $\left(\chi^{2}=7.49\right.$, $\mathrm{df}=1, p=.006)$.

We next compared the 48 sample members who currently did not meet the diagnostic cut off in any or in only one domain with the 357 who continued to meet the cut off in two or three domains. The former were more likely to be adolescents than adults $\left(\chi^{2}=6.83\right.$, $\mathrm{df}=1, p=.009$ ), more likely to currently live with their parents than in a nonfamily setting $\left(\chi^{2}=8.09\right.$, $\mathrm{df}=1, p=.004)$, and more likely to have a diagnosis of Asperger's or PDD-NOS than autism $\left(\chi^{2}=6.14\right.$, $\mathrm{df}=2, p=.046$ ). There were no gender differences between those who did and those did not meet the diagnostic cut offs currently.

\section{Changes in the Severity of Symptoms}

We next compared the severity of symptoms of the lifetime ADI-R scores with the severity of current symptoms. We also assessed the extent to which the 
difference between the lifetime and the current manifestation of symptoms varied by age cohort.

\section{Communication Domain}

The overall level of language item (see Table IIA) differentiated those who spoke in phrases of at least three words on a daily basis (scored 0 ) from those who were functionally nonverbal (scored 1 or 2). As shown in Table IIA, there was a significant time-point-bycohort interaction effect in overall level of language. Although the members of the adult cohort were more impaired in their use of language at both time points (as reflected in higher scores), they showed a sharper decline in impairment (reflecting improvement in spoken language) from the lifetime to the current score than the adolescent cohort.

Next we examined the use of nonverbal communication by both the verbal and nonverbal members of the sample. Nonverbal communication (see Table IIB) was measured by four items reflecting communication through gestures: pointing to express interest, use of conventional gestures, nodding head to signify "yes," and head shaking to indicate "no." The results of the MANOVA indicated a significant multivariate effect for time point (lifetime versus current). For both adolescents and adults, there was a significant difference between the lifetime and the current scores, with the lifetime scores reflecting substantially greater levels of impairment. Follow-up univariate tests show that for each of the four items, the lifetime score was significantly higher (signifying a greater degree of impairment) than the current score. There also was a significant multivariate effect for age cohort (adolescents versus adults). At both time points, adults had substantially greater levels of impairment. Follow-up univariate tests reveal that the adolescent cohort was less severely impaired in nonverbal communication than the adult cohort for each of the four variables at both time points.

Finally, the members of the sample who could communicate using at least three-word phrases (i.e., who scored a 0 on the overall level of language item, $n=284$ ) were included in the analysis of four verbal symptoms (see Table IIC). The items include stereotyped utterances (i.e., echolalia), inappropriate questions, pronomial reversal, and neologisms/ idiosynchratic language. The results of the MANOVA indicated a significant multivariate effect for time point. For both adolescents and adults, there was a significant difference between the lifetime and the current scores, with the lifetime scores reflecting substantially greater levels of impairment. Follow-up univariate tests show that the lifetime score was significantly higher (signifying more impairment) than the current score for each of the four verbal symptoms items. There also was a significant multivariate effect for age cohort. At both time points, there was a significant difference between adolescents and adults, with the adolescents having greater levels of impairment. Follow-up univariate tests show a significant cohort effect for only one item-inappropriate questions-for which the adolescent cohort had more severe symptoms at both time points, a departure from the cohort difference found for nonverbal communication.

There were three items measuring nonverbal communication at age 4-5 years only (spontaneous imitation, imaginative play, and imitative social play), and one item measuring verbal communication at present (reciprocal conversation; see Table IID). For the nonverbal communication items, there was a multivariate effect for age cohort, with the adult cohort more impaired at age 4-5 years than the adolescent cohort. Follow-up univariate tests show that the sample members who are currently adults were significantly less likely at age 4-5 years to evidence spontaneous imitation, imaginative play, or imitative social play than the sample members who are adolescents at present. Similarly, for the single item that rated reciprocal conversation at present, the adult cohort was significantly more impaired than the adolescent cohort.

To summarize the findings for the Communication domain, the adolescent cohort tended to be less impaired than the adult cohort in their ability to communicate nonverbally, in their ability to engage in reciprocal conversations, and in their overall level of language. However, with respect to verbal symptoms, the adolescents were more impaired than the adults, particularly in their likelihood of making inappropriate statements. For both adolescents and adults, there was a general pattern of abatement of symptoms, reflecting improved overall use of language, improved ability to communicate nonverbally, and reduced stereotyped, repetitive, or idiosyncratic speech. There was one indicator of differential improvement from the lifetime to the current rating, with the adult cohort showing a greater improvement in their overall level of language than the adolescents. 
Table II. Communication Domain

\begin{tabular}{|c|c|c|c|c|c|c|c|}
\hline & \multirow{2}{*}{\multicolumn{2}{|c|}{ Adolescent cohort }} & \multirow{2}{*}{\multicolumn{2}{|c|}{ Adult cohort }} & \multicolumn{3}{|c|}{ MANOVA/ANOVA } \\
\hline & & & & & \multirow{2}{*}{$\begin{array}{l}\text { Time point } \\
\text { (lifetime vs. } \\
\text { current) }\end{array}$} & \multirow{2}{*}{$\begin{array}{c}\text { Age cohort } \\
\text { (adolescents } \\
\text { vs. adults) }\end{array}$} & \multirow{2}{*}{$\begin{array}{c}\text { Interaction } \\
\text { (time point } \times \\
\text { cohort) }\end{array}$} \\
\hline & Lifetime & Current & Lifetime & Current & & & \\
\hline \multicolumn{8}{|c|}{ A. Overall Level of Language $(n=405)$} \\
\hline $\begin{array}{l}\text { Overall level } \\
\text { of language }\end{array}$ & 0.90 & 0.39 & 1.21 & 0.49 & $\begin{array}{c}259.35, \mathrm{p}<.001 \\
\mathrm{df}=1,403\end{array}$ & $\begin{array}{c}7.58, p=.006 \\
d f=1,403\end{array}$ & $\begin{array}{c}8.30, p=.004 \\
d f=1,403\end{array}$ \\
\hline \multicolumn{8}{|c|}{ B. Nonverbal Communication $(\mathrm{n}=396)$} \\
\hline MANOVA $^{a}$ & 6.58 & 4.63 & 7.17 & 5.68 & $\begin{array}{c}74.62, p<.001 \\
\mathrm{df}=4,391\end{array}$ & $\begin{array}{c}5.85, \mathrm{p}<.001 \\
\mathrm{df}=4,391\end{array}$ & $\mathrm{~ns}$ \\
\hline \multicolumn{8}{|c|}{ Follow-up univariate ANOVAs: } \\
\hline $\begin{array}{l}\text { Pointing to } \\
\text { express interest }\end{array}$ & 1.69 & 1.27 & 1.79 & 1.41 & $\begin{array}{c}103.98, p<.001 \\
\mathrm{df}=1,394\end{array}$ & $\begin{array}{c}5.17, p=.024 \\
\quad d f=1,394\end{array}$ & ns \\
\hline $\begin{array}{l}\text { Conventional } \\
\text { gestures }\end{array}$ & 1.87 & 1.41 & 1.95 & 1.57 & $\begin{array}{c}152.95, \mathrm{p}<.001 \\
\mathrm{df}=1,394\end{array}$ & $\begin{array}{c}6.38, p=.012 \\
d f=1,394\end{array}$ & ns \\
\hline Nodding head & 1.57 & 0.96 & 1.77 & 1.30 & $\begin{array}{c}174.12, p<.001 \\
\mathrm{df}=1,394\end{array}$ & $\begin{array}{c}18.98, p<.001 \\
\quad d f=1,394\end{array}$ & \\
\hline Head shaking & 1.45 & 1.00 & 1.66 & 1.40 & $\begin{array}{c}84.36, p<.001 \\
d f=1,394\end{array}$ & $\begin{array}{c}18.91, p<.001 \\
\text { df }=1,394\end{array}$ & $\begin{array}{c}6.06, p=.014 \\
d f=1,394\end{array}$ \\
\hline \multicolumn{8}{|c|}{ C. Verbal Symptoms $(n=284)$} \\
\hline MANOVA $^{b}$ & 4.36 & 2.95 & 4.16 & 2.89 & $\begin{array}{c}63.64, p<.001 \\
\text { df }=4,279\end{array}$ & $\begin{array}{c}3.19, p=.014 \\
d f=4,279\end{array}$ & ns \\
\hline \multicolumn{8}{|c|}{ Follow-up univariate ANOVAs: } \\
\hline $\begin{array}{l}\text { Stereotyped } \\
\text { utterances }\end{array}$ & 1.42 & & 1.41 & 1.05 & $\begin{array}{c}109.33, p<.001 \\
d f=1,282\end{array}$ & $\mathrm{~ns}$ & $\mathrm{~ns}$ \\
\hline $\begin{array}{l}\text { Inappropriate } \\
\text { questions }\end{array}$ & 1.27 & 1.01 & 0.97 & 0.72 & $\begin{array}{c}81.93, \mathrm{p}<.001 \\
\mathrm{df}=1,282\end{array}$ & $\begin{array}{c}10.40, p=.001 \\
d f=1,282\end{array}$ & $\mathrm{~ns}$ \\
\hline $\begin{array}{l}\text { Pronomial } \\
\text { reversal }\end{array}$ & 1.11 & 0.55 & 1.27 & 0.68 & $\begin{array}{c}124.74, p<.001 \\
\mathrm{df}=1,282\end{array}$ & $\mathrm{~ns}$ & $\mathrm{~ns}$ \\
\hline $\begin{array}{l}\text { Neologisms/ } \\
\text { idiosynchratic la }\end{array}$ & $\begin{array}{l}0.57 \\
\text { guage }\end{array}$ & 0.35 & 0.52 & 0.32 & $\begin{array}{c}59.76, \mathrm{p}<.001 \\
\mathrm{df}=1,282\end{array}$ & ns & $\mathrm{ns}$ \\
\hline
\end{tabular}

MANOVA/ANOVA

\begin{tabular}{ccc} 
Adolescent cohort & $\begin{array}{c}\text { Adult cohort } \\
\text { Lifetime }\end{array}$ & $\begin{array}{c}\text { Age cohort } \\
\text { (adolescents vs. } \\
\text { adults) }\end{array}$ \\
\hline
\end{tabular}

D. Communication Items Measured at One Time Point

\begin{tabular}{|c|c|c|c|}
\hline $\operatorname{MANOVA}^{c}(\mathrm{n}=405)$ & 5.20 & 5.68 & $\begin{array}{c}7.96, p<.001 \\
\mathrm{df}=3,401\end{array}$ \\
\hline \multicolumn{4}{|c|}{ Follow-up univariate ANOVAs: } \\
\hline Spontaneous imitation & 1.79 & 1.90 & $\begin{array}{c}6.79, p=.010 \\
d f=1,403\end{array}$ \\
\hline Imaginative play & 1.78 & 1.96 & $\begin{array}{c}18.17, p<.001 \\
d f=1,403\end{array}$ \\
\hline Imitative social play & 1.63 & 1.81 & $\begin{array}{c}12.51, \mathrm{p}<.001 \\
\mathrm{df}=1,403\end{array}$ \\
\hline
\end{tabular}

\begin{tabular}{lccc}
\hline $\operatorname{ANOVA}(\mathrm{n}=300)$ & Current & \multicolumn{2}{c}{ Current } \\
\hline Reciprocal conversation & 1.24 & 1.42 & $\begin{array}{c}5.12, \mathrm{p}=.024 \\
\mathrm{df}=1,298\end{array}$ \\
\hline
\end{tabular}

Note: ANOVA, analysis of variance; MANOVA, multiple ANOVA; ns, not significant.

${ }^{a}$ These summary scores are the sum of the four items in the Nonverbal Communication subscale.

${ }^{b}$ These summary scores are the sum of the four items in the Nonverbal Communication subscale.

${ }^{c}$ These summary scores are the sum of the three Communications items assessed for Lifetime only. 


\section{Reciprocal Social Interaction Domain}

Table IIIA shows the analysis of 13 items in the Reciprocal Social Interaction domain, including three items for the use of nonverbal behaviors to regulate social interaction, two items that reflect social relationships, three items that assess shared enjoyment, and five items that measure socioemotional reciprocity.

The results of the MANOVA indicate a significant multivariate effect for time point (lifetime versus current). For both adolescents and adults, there was a significant difference between the lifetime and the current scores, with the lifetime scores reflecting substantially greater levels of impairment. Follow-up univariate tests show that for all 13 items, the lifetime score was significantly higher than the current score. There also was a significant multivariate effect for age cohort, with the adults having substantially greater levels of impairment at both time points. Follow-up univariate analysis indicated that the adult cohort showed significantly more impairments in all but three items in the domain (use of other's body, inappropriate facial expressions, and using appropriate social responses).

An additional ADI-R item assessed the extent to which sample members had friendships with peers, measured at two points in time: at age 10-15 years and at present. For this analysis, sample members who at Time 1 were between the ages of 10 and 15 years were excluded, and the difference between the two time points was assessed only for those age 16 years and older. As shown in Table IIIB, impairment in the ability to sustain friendships was significantly greater at age 10-15 years than at present, and the cohort of adults was more impaired at both points in time than the cohort of adolescents.

For one item in the Reciprocal Social Interaction domain, ratings were made only at age 4-5 years (the lifetime rating): imaginative play with peers. As shown in Table IIIC, the adolescent cohort was less impaired at age 4-5 years in their ability to engage in imaginative play with peers than was the adult cohort.

To summarize the findings for the Reciprocal Social Interaction domain, the adolescent cohort was generally less impaired than the adult cohort. There was a pattern of abatement of symptoms and developmental gain between the lifetime and current ratings, reflecting improved ability to regulate social interaction, develop social relationships, share enjoyment with others, reciprocate socioemotionally, and sustain friendships.

\section{Restricted, Repetitive Behaviors and Interests Domain}

Table IVA shows the analysis of seven items in the Restricted, Repetitive Behaviors and Interests domain: circumscribed interests, unusual preoccupations, compulsions, hand and finger mannerisms, other complex mannerisms and body movements, repetitive use of objects, and unusual sensory interests. The results of the MANOVA indicated a significant multivariate interaction effect of time point by age cohort. Follow-up univariate tests show that for two items-unusual preoccupations and complex mannerisms-the adult cohort had a sharper decline in symptoms from the lifetime to the current score than did the adolescent cohort. Note that the adults' current ratings were less impaired than the adolescents' rating on all items in this domain.

We analyzed the verbal rituals item only for sample members who communicated in at least three-word phrases. For this subsample $(n=299)$, there was a main effect for time point, with significantly less impairment evident at this time than in the lifetime score.

To summarize, the adults were less symptomatic than the adolescents at both time points with respect to restricted, repetitive behaviors and interests. There was a pattern of differential reduction in the severity of symptoms between the lifetime and current ratings between the two age cohorts for unusual preoccupations and complex mannerisms, for which the adult cohort showed a sharper abatement of symptoms than did the adolescent cohort.

\section{Symptom-Level Change}

The third approach we used to understand the pattern of symptoms in adolescence and adulthood was to examine the difference between lifetime and current scores for each symptom. Specifically, we examined the likelihood that the sample members who scored at or above the symptomatic threshold for the lifetime score for each item were not symptomatic at present. (We note that being asymptomatic does not necessarily signify the absence of impairment, but rather indicates a level of impairment not diagnostic of autism, based on the ADI-R standards.) Table V portrays these data for each of the three ADI-R domains.

\section{Communication Domain}

For the items in the Communication domain (see Table VA), there was substantial abatement of 
Table III. Reciprocal Social Interaction Domain

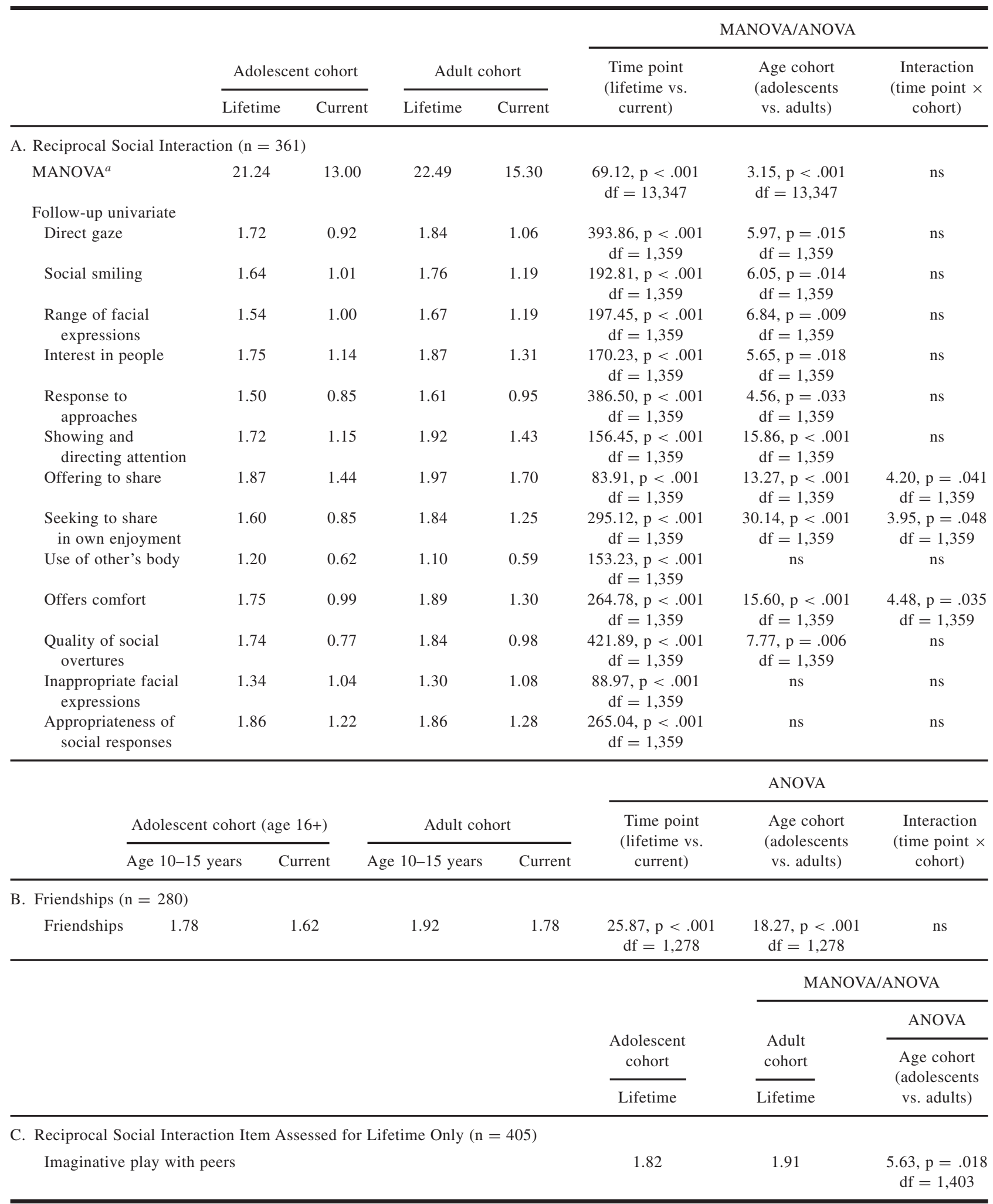

Note: ANOVA, analysis of variance; MANOVA, multiple ANOVA; ns, not significant.

${ }^{a}$ These summary scores are the sum of the four items in the Nonverbal Communication subscale.

${ }^{b}$ These summary scores are the sum of the seven items in the Repetitive Behavior and Stereotyped Interests subscale. 
Table IV. Repetitive Behavior and Stereotyped Interests Domain

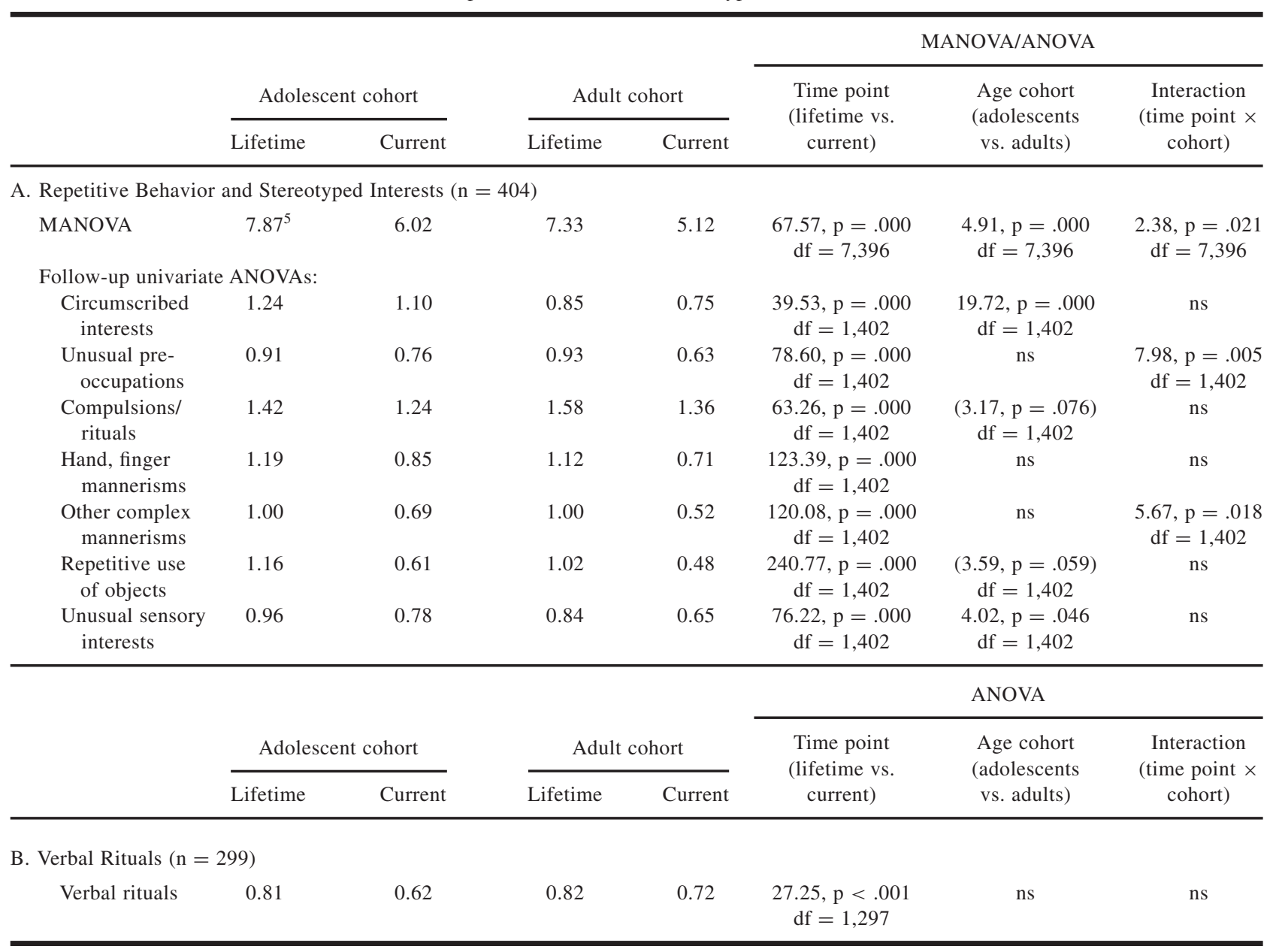

Note: ANOVA, analysis of variance; ns, not significant.

${ }^{5}$ These summary scores reflect the sum of the scores for the 7 items in the Repetitive Behavior and Stereotyped Interests sub-scale.

symptoms from the lifetime to the current score. This reflects a reduction by an average of about $25 \%$ in the percentage of the sample members who were symptomatic. The greatest improvement was evident for the overall level of language item, with nearly two-thirds $(60.2 \%)$ of those who were not able to speak in threeword phrases on a daily basis at age $4-5$ years currently able to do so. There was also substantial abatement of the symptom of pronomial reversal, with $45.5 \%$ of those who had abnormal lifetime ratings (i.e., who ever scored 1 or 2) currently asymptomatic (currently scoring 0 ). About one-third (33.8\%) of those who had abnormal lifetime ratings for neologisms/idiosynchratic language scored 0 at present, and about one-quarter $(24.6 \%)$ of those members who were unable to communicate via nodding head "yes" at age 4-5 years were able to do so at present.
In contrast, there was greater stability over time in impairments in communication via head shaking, pointing to express interest, stereotyped utterances, use of conventional gestures, and inappropriate questions, with fewer than $20 \%$ of those who were symptomatic for the lifetime diagnostic rating for these items no longer symptomatic. The least improvement was reflected in inappropriate questions, with only $8.3 \%$ of those who were once symptomatic currently asymptomatic.

The numbers in parentheses in Table VA show the number of individuals in the sample who were ever symptomatic (i.e., lifetime scores of 1 or 2) with respect to each of the Communication domain items. This number varied greatly, with as many as 398 (98.3\%) of the 405 sample members ever manifesting abnormalities in the use of gestures but only 130 
Table V. Percentage of Sample Members Who Were Symptomatic for the Lifetime Score Who Became Asymptomatic at the Current Ratings

\begin{tabular}{|c|c|c|c|c|}
\hline & $\begin{array}{l}\text { All cases } \\
(\mathrm{n}=405)\end{array}$ & $\begin{array}{l}\text { Age } 10-21 \text { years } \\
\quad(\mathrm{n}=251)\end{array}$ & $\begin{array}{l}\text { Age } 22-53 \text { years } \\
\quad(\mathrm{n}=154)\end{array}$ & $\begin{array}{l}\chi^{2} \text { (adolescents } \\
\text { vs. adults) }\end{array}$ \\
\hline \multicolumn{5}{|l|}{ A. Communication Domain } \\
\hline Overall level of language (4-5 years) & $60.2 \%(259)$ & $61.6 \%(146)$ & $58.4 \%(113)$ & ns \\
\hline Pronominal reversal (ever) & $45.5 \%(191)$ & $47.9 \%(119)$ & $41.7 \%(72)$ & ns \\
\hline $\begin{array}{l}\text { Neologisms/idiosynchratic language } \\
\quad \text { (ever) }\end{array}$ & $33.8 \%(130)$ & $32.6 \%(86)$ & $36.4 \%(44)$ & ns \\
\hline Nodding head ( $4-5$ years $)$ & $24.6 \%(366)$ & $29.7 \%(222)$ & $16.7 \%(144)$ & $\begin{array}{l}8.04, \mathrm{df}=1 \\
\mathrm{p}=.005\end{array}$ \\
\hline Head shaking ( $4-5$ years) & $18.2 \%(341)$ & $23.4 \%(205)$ & $10.3 \%(136)$ & $\begin{array}{l}9.46, \mathrm{df}=1 \\
\mathrm{p}=.002\end{array}$ \\
\hline Pointing to express interest ( $4-5$ years) & $15.6 \%(390)$ & $15.8 \%(241)$ & $15.4 \%(149)$ & ns \\
\hline Stereotyped utterances (ever) & $14.7 \%(245)$ & $15.1 \%(166)$ & $12.1 \%(91)$ & ns \\
\hline Conventional gestures ( $4-5$ years) & $11.3 \%(398)$ & $13.1 \%(245)$ & $8.5 \%(153)$ & ns \\
\hline Inappropriate questions (ever) & $8.3 \%(216)$ & $6.1 \%(148)$ & $13.2 \%(68)$ & \\
\hline Mean for domain & $25.7 \%$ & $27.2 \%$ & $23.3 \%$ & \\
\hline \multicolumn{5}{|l|}{ B. Reciprocal Social Interactions } \\
\hline Use of other's body (ever) & $42.7 \%(267)$ & $42.8 \%(173)$ & $42.6 \%(94)$ & ns \\
\hline $\begin{array}{l}\text { Quality of social overtures } \\
\text { (4-5 years })\end{array}$ & $36.5 \%(375)$ & $40.7 \%(231)$ & $29.9 \%(144)$ & $\begin{array}{c}4.49, \mathrm{df}=1 \\
\mathrm{p}=.034\end{array}$ \\
\hline Offers comfort ( $4-5$ years) & $26.3 \%(388)$ & $31.2 \%(237)$ & $18.5 \%(151)$ & $\begin{array}{l}7.65, \mathrm{df}=1 \\
\mathrm{p}=.006\end{array}$ \\
\hline $\begin{array}{l}\text { Seeking to share in own enjoyment } \\
\text { ( } 4-5 \text { years })\end{array}$ & $23.6 \%(386)$ & $29.1 \%(234)$ & $15.1 \%(152)$ & $\begin{array}{l}9.92, \mathrm{df}=1 \\
\mathrm{p}=.002\end{array}$ \\
\hline Interest in people ( $4-5$ years) & $21.3 \%(381)$ & $24.6 \%(232)$ & $16.1 \%(149)$ & $\begin{array}{c}3.88, \mathrm{df}=1 \\
\mathrm{p}=.049\end{array}$ \\
\hline Direct gaze ( $4-5$ years) & $21.2 \%(386)$ & $21.9 \%(237)$ & $20.1 \%(149)$ & $\mathrm{ns}$ \\
\hline $\begin{array}{l}\text { Showing and directing attention } \\
(4-5 \text { years })\end{array}$ & $21.0 \%(386)$ & $23.8 \%(235)$ & $16.6 \%(151)$ & ns \\
\hline Social smiling (4-5 years) & $20.1 \%(379)$ & $21.9 \%(233)$ & $17.1 \%$ & $\mathrm{~ns}$ \\
\hline Response to approaches (4-5 years) & $14.4 \%(388)$ & $15.6 \%(237)$ & $12.6 \%(151)$ & ns \\
\hline $\begin{array}{l}\text { Range of facial expression } \\
\quad(4-5 \text { years })\end{array}$ & $13.6 \%(369)$ & $16.5 \%(224)$ & $9.0 \%(145)$ & $\begin{array}{c}4.29, \mathrm{df}=1 \\
\mathrm{p}=.038\end{array}$ \\
\hline $\begin{array}{l}\text { Appropriateness of social responses } \\
\text { (4-5 years) }\end{array}$ & $12.3 \%(399)$ & $12.1 \%(247)$ & $12.5 \%(152)$ & ns \\
\hline Offering to share ( $4-5$ years) & $11.6 \%(395)$ & $14.9 \%(242)$ & $6.5 \%(153)$ & $\begin{array}{c}6.34, \mathrm{df}=1 \\
\mathrm{p}=.012\end{array}$ \\
\hline $\begin{array}{l}\text { Inappropriate facial expressions } \\
\quad \text { (ever) }\end{array}$ & $9.6 \%(355)$ & $10.3 \%(224)$ & $8.4 \%(131)$ & ns \\
\hline Friendships (10-15 years) & $4.4 \%(275)$ & $7.3 \%(124)$ & $2.0 \%(151)$ & $4.55, \mathrm{p}=.033$ \\
\hline Mean for domain & $19.9 \%$ & $22.3 \%$ & $16.2 \%$ & \\
\hline \multicolumn{5}{|c|}{ C. Restricted, Repetitive Behaviors and Interests } \\
\hline Repetitive use of objects (ever) & $46.0 \%(302)$ & $44.8 \%(194)$ & $48.1 \%(108)$ & ns \\
\hline Other complex mannerisms (ever) & $33.1 \%(236)$ & $27.6 \%(145)$ & $41.8 \%(91)$ & $\begin{array}{c}5.08, \mathrm{df}=1 \\
\mathrm{p}=.024\end{array}$ \\
\hline Hand/finger mannerisms (ever) & $23.8 \%(277)$ & $21.1 \%(175)$ & $28.4 \%(102)$ & ns \\
\hline Unusual preoccupations (ever) & $19.1 \%(235)$ & $14.9 \%(141)$ & $25.5 \%(94)$ & $\begin{array}{l}4.12, \mathrm{df}=1 \\
\mathrm{p}=.042\end{array}$ \\
\hline Unusual sensory interests (ever) & $14.4 \%(298)$ & $14.4 \%(194)$ & $14.4 \%(104)$ & ns \\
\hline Verbal rituals (ever) & $13.9 \%(158)$ & $16.5 \%(97)$ & $9.8 \%(61)$ & ns \\
\hline Compulsions/rituals (ever) & $9.8 \%(338)$ & $9.9 \%(202)$ & $9.6 \%(136)$ & ns \\
\hline Circumscribed interests (ever) & $6.1 \%(277)$ & $5.8 \%(189)$ & $6.8 \%(88)$ & ns \\
\hline Mean for domain & $20.8 \%$ & $19.4 \%$ & $23.1 \%$ & \\
\hline
\end{tabular}

Note: ns, not significant.

The numbers in parentheses are a count of the cases who were symptomatic for the lifetime rating. 
sample members $(32.1 \%)$ ever symptomatic for using neologisms.

For two items in the Communication domain, there was a differential pattern manifested by the adolescent versus the adult cohorts: nodding head "yes" and head shaking "no." For these two items, a significantly greater proportion of the adolescent cohort became asymptomatic than the adult cohort.

\section{Reciprocal Social Interaction Domain}

For the items in the Reciprocal Social Interaction domain, there was substantial abatement of symptoms from the lifetime to the current score, reflecting a reduction by about $20 \%$ in the sample who were symptomatic. About two-fifths (42.7\%) of the sample members who at their most severe degree of impairment used other people's bodies instrumentally no longer did so. About one-third $(36.5 \%)$ were now asymptomatic in the quality of their social overtures, and about one-quarter were able to offer comfort $(26.3 \%)$ and seek to share in own enjoyment (23.6\%) at present but in the past were not able to do so. Of those not able to show an interest in people, manifest a direct gaze, show and direct attention, or manifest social smiling for their lifetime ratings, at least $20 \%$ were able to do so at present.

A pattern of greater stability was characteristic of the other six Reciprocal Social Interaction items (response to approaches, range of facial expressions, appropriateness of social responses, offering to share, inappropriate facial expressions, and friendships), with fewer than $20 \%$ of those who scored as symptomatic on each of these items for the lifetime rating no longer symptomatic. Only $4.4 \%$ of those who did not have a peer friendship at age 10-15 years currently had such a relationship.

The number of individuals in the sample who were ever symptomatic in the Reciprocal Social Interaction domain ranged from 399 (98.5\% of the sample) who were impaired in the appropriateness of social responses to 267 (65.9\%) who used other people's bodies instrumentally.

For seven items in the Reciprocal Social Interaction domain, there was a differential pattern manifested by the adolescent versus the adult cohorts, with a significantly greater proportion of the adolescents becoming asymptomatic than the adults. These items were quality of social overtures, offering comfort, seeking to share enjoyment, interest in people, range of facial expression, offering to share, and having friendships.

\section{Restricted, Repetitive Behaviors and Interests Domain}

For the Restricted, Repetitive Behaviors and Interests domain, the greatest degree of improvement was observed in the repetitive use of objects, with nearly half (46.0\%) of those who were symptomatic for the lifetime score no longer symptomatic. One-third (33.1\%) of those who ever scored as symptomatic for the manifestation of complex mannerisms were not currently symptomatic, and about one-quarter (23.8\%) made such improvements with respect to hand and finger mannerisms.

Other symptoms in this domain were less likely to improve. Less than $20 \%$ of those ever scoring symptomatic were no longer symptomatic with respect to unusual preoccupations, unusual sensory interests, verbal rituals, compulsions/rituals, and circumscribed interests.

Comparatively few sample members $(n=158$, $39.0 \%$ ) ever engaged in verbal rituals, although many more $(\mathrm{n}=338,83.2 \%)$ engaged in compulsions and rituals.

For two items in the Restricted, Repetitive Behaviors and Interests domain, there was a differential pattern of symptom abatement manifested by the adolescent versus the adult cohort. A significantly greater proportion of the adult cohort became asymptomatic in complex mannerisms and unusual preoccupations than the adolescent cohort.

We checked across all three domains to determine whether sample members who initially were asymptomatic became symptomatic in adolescence or adulthood, but only 47 sample members evidenced this reverse pattern on even one symptom. Thus, the overall phenomenon of symptom abatement overshadowed much less prevalent instances of worsening of symptoms.

\section{DISCUSSION}

The multiple perspectives taken in this study converge to support a pattern of improvement from childhood to adolescence and adulthood, with differences between the adolescent and adult cohorts in their degree of improvement and manifestation of current symptoms. These findings may be reflective of different diagnostic practices in use at different historical time points (Volkmar et al., 1992), differential treatments and services available at different times in the past (Lord \& McGee, 2001), as well as developmental changes that may occur between 
adolescence and adulthood in individuals who have an ASD diagnosis (Howlin, Mawhood, \& Rutter, 2000; Mawhood, Howlin, \& Rutter, 2000). These are not necessarily competing explanations, with all three processes possibly influencing current cohort differences.

Specifically, the adolescent and the adult cohorts differed in the manifestation of the symptoms of autism, with cohort difference varying according to domain. The adolescent cohort was less impaired than the adult cohort with respect to the Reciprocal Social Interaction domain but more impaired with respect to the Restricted, Repetitive Behaviors and Interests domain, with a mixed pattern for Communication.

Apart from cohort differences, the findings of this analysis point to large improvements (retrospectively assessed) across domains in the functioning of adolescents and adults who as children received a diagnosis on the autism spectrum. When current scores were used, only about half of the sample met ADI-R criteria for Autistic Disorder, and a small number (11.9\%) showed a pattern of impairment on the ADI-R that no longer was indicative of any diagnosis on the autism spectrum. Lifetime versus current ratings were significantly different for all domains. At least $20 \%$ of the sample who manifested clinically significant symptoms in each domain for the lifetime rating were reported as asymptomatic in adolescence or adulthood. Thus, differences were sufficiently large to infer clinical as well as statistical significance. This pattern of improvement in functioning and abatement of symptoms is consistent with past studies, using case study (e.g., Sperry, 2001), prospective (e.g., Beadle-Brown et al., 2000), and retrospective (e.g., Boelte \& Poustka, 2000) methods of data collection.

Although cross-sectional comparisons and retrospective reports are notoriously weak grounds for inferring change over time, future prospective investigations can test some specific hypotheses generated here. First, the adult cohort appeared at present to be less severely impaired than the adolescent cohort in the manifestation of abnormal symptoms, including verbal symptoms and many restricted, repetitive behaviors and interests. It is possible that the developmental course of the abnormal behaviors of autism is one of abatement of symptoms from adolescence into adulthood. This pattern is similar to the course of schizophrenia, in which positive symptoms (bizarre behavior, hallucinations, delusions) tend to abate over time (Schultz et al., 1997).

In contrast, the adolescent cohort appears to be less impaired than the adult cohort in the manifesta- tion of prosocial behaviors, such as communication and social interaction. Three processes might underlie this cohort difference: developmental intensification of symptoms, improved services available to younger cohorts, or changes in diagnostic practices. Regarding the first of these, the limited available prospective data (e.g., Beadle-Brown et al., 2000; Mawhood et al., 2000; Persson, 2000) indicate that adults with autism show gains in interpersonal behavior and communication. The literature would lead us to expect continued development in social and communicative skills from adolescence to adulthood in individuals with autism, rather than the pattern of poorer functioning of adults than adolescents that was evident in this sample.

Another explanation for the better prosocial behavior in the adolescents than adults in this sample is that the services currently available to the younger cohort are more intense and specific to autism than in the past (Dawson \& Osterling, 1997; Lord \& McGee, 2001; Rogers, 1996). More widely available, intensive, and focused services might account for the adolescents' advantage in communication and reciprocal social interaction.

In addition, changing diagnostic practices (Volkmar et al., 1992) have resulted in the inclusion of individuals with less severe language impairments in younger cohorts than in the older groups. Broadening the autism spectrum to include PDD-NOS and Asperger's Syndrome has also led to the diagnosis of less-impaired individuals than prior diagnostic formulations. If less-impaired individuals make greater gains over time (Howlin \& Goode, 1998), then it is possible that the advantage evident in the adolescent cohort of this study in social interaction reflects their higher initial level of functioning in these domains than the adult cohort, rather than the developmental course of autism symptoms.

Unfortunately, the retrospective data reported here that were collected at Time 1 of our study do not permit these tentative interpretations to be verified. In contrast, the longitudinal design of this ongoing study, with repeated ADI-R measures to be administered over a 5-year period, will add additional insight into the short-term developmental course of the core symptoms of ASDs within cohorts of adolescents and adults.

The phenomenon of overall symptom abatement and improvement in functioning that we report in this article and that has been reported in prior studies should not overshadow the evidence that for most persons, ASDs are lifelong disabilities. In addition, 
although only about one-half of the present sample members' ADI-R scores currently meet the lifetime diagnostic criteria for Autistic Disorder, this does not imply that the diagnosis is inaccurate, as it is not valid to use current ratings diagnostically. Rather, the diagnostic criteria of the DSM-IV as operationalized by the ADI-R are optimally applied when the child is young, and many ADI-R items are tied specifically to age $4-5$ years. That the disorder changes in its manifestation over the life course does not, therefore, indicate that affected individuals have any less of a need for services and supports as they move through adolescence into adulthood and midlife than they did in childhood. Rather, developmentally appropriate services are needed for adolescents and adults with ASD diagnoses.

This sample included both individuals who were coresiding with their parents and those who lived away from home, with a greater proportion of the adult cohort living out of the home as compared with the adolescent cohort. Thus, it is possible that coresidence status confounded the ADI-R cohort differences reported here. To assess this possibility, we reran the analyses in Tables II-IV, controlling for place of residence (with parents or elsewhere). The pattern of domain-score cohort differences was unchanged with respect to the Reciprocal Social Interaction and Repetitive Behavior and Stereotyped Interests domains. For the Communication domain, the pattern of findings regarding nonverbal communication was unchanged, but the cohort differences for overall level of language and the verbal symptoms subscale became nonsignificant. Thus, controlling for place of residence had little influence on the cohort differences reported here, with the possible exception of the Communication domain.

There are several limitations of this research. One set of limitations pertains to sampling techniques. The volunteer sample limits the generalizability of results. Also, the sample contains very few non-Whites (only about $7 \%$ ), so generalization to more diverse groups should be avoided. Furthermore Massachusetts and Wisconsin are relatively enriched service environments, ranking ninth and thirteenth, respectively, among the states in their fiscal effort for MR/DD services in 1998 (Braddock, Hemp, Parish, \& Rizzolo, 2000), which may have enhanced the pattern of improved functioning over the life course. Furthermore, because the participants in our study were drawn from the community, not from a clinical roster, as was characteristic of most prior studies (e.g., Mawhood et al., 2000; Piven et al., 1996), it is likely that they have less severe current manifestation of symptoms than would be evident in clinical populations. Indeed, our sample had more advanced communication abilities than has been reported in the literature. For example, Lord and Paul (1997) quote a "well-circulated statistic" that about $50 \%$ of individuals with autism will eventually have useful speech (p. 203), whereas in this sample, the percentage is about $70 \%$ (284 of the sample used three-word phrases on a daily basis). Similarly, in Piven et al.,'s (1996) sample, 13\% no longer met the criteria for autism, whereas in this sample, the percentage who improved to this extent was $45 \%$. Thus, the pattern of improvement reported in this study is consistent with past research, but the greater degree of improvement might be a function of the enriched service environment and a community rather than a clinical sample.

Another limitation derives from the retrospective data collected for the ADI-R. Although parental memory is subject to bias, we think there is value in parental assessments of symptoms in the context of investigatorbased interviews. Indeed, there is a solid empirical base for the reliability and validity of diagnostic interviewing when data are elicited using investigator-based methods (Angold, 2002; Cox, Hopkinson, \& Rutter, 1981; Cox, Rutter, \& Holbrook, 1981; Rutter, Cox, Egert, Holbrook, \& Everitt, 1981), such as the ADI-R. Furthermore, studies of the cognitive bases of interviews, although mindful of the limits of retrospective questions, also note that "much of the research demonstrates relatively accurate recall" (Pearson, Ross, \& Dawes, 1992, p. 86).

A related issue is the duration of the recalled period. Although the ADI-R is used most often with parents of young children who are asked to recall behaviors that occurred recently, it has also been used extensively in research (as well as clinically) with adolescent and adult populations (see Boelte \& Proustka, 2000; Hill et al., 2001; Lord et al., 1997; Piven et al., 1996). In fact, one of the advantages of the ADI-R is that it was designed to be used for individuals of all ages, with only a few age-specific items. Thus, changes over time can be tracked, without the need to change measures across the life course. Nevertheless, questions must be acknowledged about the validity of retrospective reports of behavior (Angold, Erkanli, Costello, \& Rutter, 1996) that temper this study's conclusions and warrant prospective investigations.

Juxtaposed against these limitations are several strengths of this research, including its large sample size; the age range of the sample, which spans over 
40 years in the life course of individuals with autism spectrum disorders; its use of a community rather than a clinical sample; and its administration of a standardized measure that was designed to be applied across ages. Furthermore, this study sought to offer descriptive data about understudied stages of life in individuals with autism spectrum disorders. There is a need for continued prospective research on the symptoms of ASD in adolescence and adulthood to enhance basic understanding of the life course trajectory of this disorder, to facilitate service development, and to support families in their long-range planning efforts.

\section{ACKNOWLEDGMENTS}

Support for the preparation of this manuscript was provided by the National Institute on Aging (R01 AG08768), the National Institute of Disability and Rehabilitation Research through the Rehabilitation Research and Training Center on Aging with Developmental Disabilities at the University of Illinois at Chicago (H133B30069), the National Institute of Child Health and Human Development (T32 HD07489), the Graduate School and the Waisman Center of the University of Wisconsin-Madison, and the Starr Center for Mental Retardation at the Heller School at Brandeis University. We are also extremely grateful to the families who participated so generously in this research.

\section{REFERENCES}

American Psychiatric Association. (1994). Diagnostic and statistical manual of mental disorders (4th ed.). Washington, DC: Author.

American Psychiatric Association. (2000). Diagnostic and statistical manual of mental disorders (4th ed., text revision). Washington, DC: Author

Angold, A. (2002). Diagnostic interviews with parents and children. In M. Rutter \& E. Taylor (Eds.), Child and adolescent psychiatry (4th ed., pp. 32-51). Oxford: Blackwell.

Angold, A., Erkanli, A., Costello, E. J., \& Rutter, M. (1996). Precision, reliability, and accuracy in the dating of symptom onsets in child and adolescent psychopathology. Journal of Child Psychology and Psychiatry and Allied Disciplines, 37, 657-664.

Beadle-Brown, J., Murphy, G., Wing, L., Gould, J., Shah, A., \& Holmes, N. (2000). Changes in skills for people with intellectual disability: A follow-up of the Camberwell cohort. Journal of Intellectual Disability Research, 44, 12-24.

Boelte, S., \& Poustka, F. (2000). Diagnosis of autism: The connection between current and historical information. Autism, 4, 382-390.

Braddock, D., Hemp, R., Parish, S., \& Rizzolo, M. C. (2000). The state of the states in developmental disabilities: 2000 study summary. Chicago: University of Illinois at Chicago, Department of Disabilities and Human Development.

Burack, J. A., Charman, T., Yirmiya, N., \& Zelazo, P. R. (2001). Development and autism: Messages from developmental psychopathology. In J. A. Burack \& T. Charman (Eds.), The development of autism: Perspectives from theory and research (pp. 3-15). Mahwah, NJ: Lawrence Erlbaum.

Cox, A., Hopkinson, K., \& Rutter, M. (1981). Psychiatric interviewing techniques: II. Naturalistic study: Eliciting factual information. British Journal of Psychiatry, 138, 283-291.

Cox, A., Rutter, M., \& Holbrook, D. (1981). Psychiatric interviewing techniques: V. Experimental study: Eliciting factual information. British Journal of Psychiatry, 139, 29-37.

Dawson, G., \& Osterling, J. (1997). Early intervention in autism. In M. J. Guralnick (Ed.) The effectiveness of early intervention (pp. 307-326). Baltimore, MD: Paul H. Brookes.

Fombonne, E. (2001). Is there an epidemic of autism? Pediatrics, 107, 411-413.

Fong, L., Wilgosh, L., \& Sobsey, D. (1993). The experience of parenting an adolescent with autism. International Journal of Disability, Development, and Education, 40, 105-113.

Gilchrist, A., Green, J., Cox, A., Burton, D., Rutter, M., \& LeCouteur, A. (2001). Development and current functioning in adolescents with Asperger Syndrome: A comparative study. Journal of Child Psychology and Psychiatry, 42, 227-240.

Gillberg, C., \& Steffenberg, S. (1987). Outcome and prognostic factors in infantile autism and similar conditions: A populationbased study of 46 cases followed through puberty. Journal of Autism and Developmental Disorders, 17, 273-287.

Hill, A., Boelte, S., Petrova, G., Beltcheva, D., Tacheva, S., \& Poustka, F. (2001). Stability and interpersonal agreement of the interviewbased diagnosis of autism. Psychopathology, 34, 187-191.

Howlin, P., \& Goode, S. (1998). Outcome in adult life for people with autism and Asperger's syndrome. In F. R. Volkmar (Ed.), Autism and pervasive developmental disorders. Cambridge monographs in child and adolescent psychiatry (pp. 209-241). New York: Cambridge University Press.

Howlin, P., Mawhood, L., \& Rutter, M. (2000). Autism and developmental receptive language disorder-a follow-up comparison in early adult life. II: Social, behavioural, and psychiatric outcomes. Journal of Child Psychology and Psychiatry, 41, $561-578$.

Kanner, L. (1971). Follow-up study of eleven autistic children originally reported in 1943. Journal of Autism and Childhood Schizophrenia, 1, 119-145.

Kobayashi, R., \& Murata, T. (1998). Behavioral characteristics of 187 young adults with autism. Psychiatry and Clinical Neurosciences, 52, 383-390.

Lord, C., \& McGee, W. (2001). Educating children with autism. Committee on Educational Interventions for Children with Autism. Division of Behavioral and Social Sciences and Education. Washington, DC: National Academy Press.

Lord, C., \& Paul, R. (1997). Language and communication in autism. In D. J. Cohen \& F. R. Volkmar (Eds.), Handbook of autism and pervasive developmental disorders (pp. 195-225). New York: Wiley.

Lord, C., Pickles, A., McLennan, J., Rutter, M., Bregman, J., Folstein, S., Fombonne, E., Leboyer, M., \& Minshew, N. (1997). Diagnosing autism: Analyses of data from the Autistic Diagnostic Interview. Journal of Autism and Developmental Disorders, 27, 501-517.

Lord, C., Rutter, M., \& LeCouteur, A. (1994). Autism diagnostic interview-revised: A revised version of a diagnostic interview for caregivers of individuals with possible pervasive developmental disorders. Journal of Autism and Developmental Disorders, 24, 659-685.

Loveland, K. A. (2001). Toward an ecological theory of autism. In J. A. Burack \& T. Charman (Eds.), The development of autism: Perspectives from theory and research (pp. 17-37). Mahwah, NJ: Lawrence Erlbaum.

Magnusson, P., \& Saemundsen, E. (2001). Prevalence of autism in Iceland. Journal of Autism and Developmental Disorders, 31, $153-163$. 
Mawhood, L., Howlin, P., \& Rutter, M. (2000). Autism and developmental receptive language disorder-a comparative followup in early adult life. I: Cognitive and language outcomes. Journal of Child Psychology and Psychiatry, 41, 547-559.

Pearson, R. W., Ross, M., \& Dawes, R. M. (1992). Personal recall and the limits of retrospective questions in surveys. In J. M. Tanur (Ed.), Questions about questions: Inquiries into the cognitive basis of surveys (pp. 65-94). New York: Russell Sage Foundation.

Persson, B. (2000). A longitudinal study of quality of life and independence among adult men with autism. Journal of Autism and Developmental Disorders, 30, 61-66.

Piven, J., Harper, J., Palmer, P., \& Arndt, S. (1996). Course of behavioral change in autism. A retrospective study of high-IQ adolescents and adults. Journal of the Academy of Child and Adolescent Psychiatry, 35, 523-529.

Rogers, S. J. (1996). Early intervention in autism. Journal of Autism and Developmental Disorders, 26, 243-246.

Rumsey, J. M., Rapoport, M. D., \& Sceery, W. R. (1985). Autistic children as adults: Psychiatric, social, and behavioral outcomes. Journal of the Academy of Child Psychiatry, 24, 465-473.

Rutter, M., Cox, A., Egert, S., Holbrook, D., \& Everitt, B. (1981). Psychiatric interviewing techniques: IV. Experimental study: Four contrasting styles. British Journal of Psychiatry, 138, $456-465$.

Schroeder, S. R., \& LeBlanc, J. M. (1996). A life-span perspective on the development of individuals with autism. Journal of Autism and Developmental Disorders, 26, 251-255.
Schultz, S. K., Miller, D. D., Olvers, S. E., Arndt, S., Fraum, M., \& Andreasen, N. C. (1997). The life course of schizophrenia: Age and symptom dimensions. Schizophrenia Research, 23, 15-23.

Sperry, V. W. (2001). Fragile success: Ten autistic children, childhood to adulthood. Baltimore, MD: Paul H. Brookes.

Tantam, D. (2000). Adolescence and adulthood of individuals with Asperger syndrome. In A. Klin \& F. R. Volkmar (Eds.), Asperger syndrome (pp. 367-399). New York: Guilford Press.

Travis, L. L., \& Sigman, M. (1998). Social deficits and interpersonal relationships in autism. Mental Retardation and Developmental Disabilities Research Reviews, 4, 65-72.

Venter, A., Lord, C., \& Schopler, E. (1992). A follow-up study of high-functioning autistic children. Journal of Child Psychology and Psychiatry and Allied Disciplines, 33, 489-507.

Volkmar, F. R., Cicchetti, D. V., Bregman, J., \& Cohen, D. J. (1992). Three diagnostic systems for autism: DSM-III, DSM-III-R, and ICD-10. Journal of Autism and Developmental Disorders, 22, 483-492.

Wing, L. (1993). The definition and prevalence of autism: A review. European Child and Adolescent Psychiatry, 2, 61-74.

Wolf, L., \& Goldberg, B. (1986). Autistic children grow up: An eight to twenty-four year follow-up study. Canadian Journal of Psychiatry, 31, 550-556.

World Health Organization. (1990). ICD-10: International statistical classification of diseases and related health problems. Geneva: Author. 